\title{
On the Guidance of Red Film to the Values of Contemporary College Students
}

\author{
Qi Huanhui Zhao Jianhua
}

School of Journalism and Communication, Jiangxi Normal University, Changsha, Jiangxi Province, China

252532820@qq.com

Keywords: Red Film; College Students; Values; Guidance

Abstract. Red movies, as a new force in the Chinese film market, have repeatedly set box office records in recent years. While being accepted by the market, red movies play a vital role in the dissemination of red culture, and college students, as the main consumer groups in the film market, will also be affected by red movies. Through the analysis of the box office of the red film and the film itself, it is found that the red film itself plays a guiding and shaping role in the values of contemporary college students.

\section{红色电影对当代大学生价值观的引导探讨}

\author{
齐英珲 赵剑华 \\ 江西师范大学新闻与传播学院, 江西南昌, 中国
}

关键词: 红色电影; 大学生; 价值观; 引导

中文摘要: 红色电影作为中国电影市场的一支生力军, 近年来屡创票房纪录。在被市场接受 的同时, 红色电影对于红色文化的传播起到了至关重要的作用, 而大学生作为电影市场的主 要消费群体, 也会受到红色电影的影响。通过对红色电影票房以及电影本身进行分析, 发现 红色电影本身对当代大学生价值观的引导和塑造作用。

\section{1.个性鲜明的红色电影}

\section{1 红色电影概念}

电影艺术作为最为年轻的艺术之一，在如今社会当中越来越受人们的追捧。在世界电影 史当中，电影诞生于 1895 年法国巴黎的一家咖啡馆中，卢米埃尔兄弟所拍摄的《工厂大门》 《火车进站》《水浇园丁》等短片成为世界上最早的一批电影作品, 也象征着电影正式进入 人们的视野。1911 年意大利诗人和电影先驱者乔托·卡努杜发表了一篇名为《第七艺术宣言》 的论著, 他在世界电影史上第一次宣称电影是一种表演艺术, 从此“第七艺术”成为了电影艺 术的有一代名词。

红色电影作为中国独有的电影种类，在内容，文化背景，精神内涵上区别于其他电影种 类。其内容大多与中华民族近代以来不屈抗争及新中国成立之后广大人民的努力奋斗相关, 主要表达对于中华民族儿女不屈抗争的歌颂, 以及对美好生活的向往。影片大多数展现了革 命精神以及中华儿女坚韧不屈的思想风貌。将中华民族的优秀精神内核与电影艺术相结合, 使人们能够更好，更真切的感受到深厚的民族文化内涵。 


\section{2 红色电影发展现状}

电影票房不失为衡量电影发展的方法之一。近年来，国内电影市场蓬勃发展，根据国家 电影局日前发布的数据显示 2018 年国内电影市场总票房达到了 609.76 亿元，同比增长 $9.06 \%$ 。 票房排名前五的影片当中，四部为国产电影，其中红色电影《红海行动》以 36.5 亿的票房高 举榜首，成为当年票房冠军，并引起了社会对于中国军人以及世界和平的广泛讨论。

纵观 10 年电影票房排行, 红色电影的发展使显而易见的。从 2011 年的《辛亥革命》票 房仅四千万左右，排名当年票房排行的 63 位。再到 2017 年的《战狼 2》, 以 56.8 亿元的惊人 票房力压好莱坞影片《速度与激情 $8 》$ 成为当年票房冠军。

这与近些年来电影市场的蓬勃发展是离不开的。前三名电影当中, 《战狼 $2 》$ 与《红海行 动》分列第一与第三, 票房之和超过了 92 亿元, 接近百亿。以上票房数据足以看出, 红色 电影近些年来的蓬勃发展。

\section{3 红色电影特点}

红色电影, 作为具有中国特色的电影种类。在艺术手法, 影片内容以及精神内涵上都有 着自己的独有的特点。

影片内容是一部电影中分量极重的一个部分，好的故事在进过艺术手法的再创造往往能 给观众带来非凡的影视体验。红色电影的内容多为历史事件改变, 如《湄公河行动》则是对 于我国边境缉毒民警工作日常以及工作环境的再创造, 《红海行动》则是直接对也门撤侨事 件进行改编。影片内容独特的同时，也对艺术手法上的选择起到了很大程度的影响。

因为影片内容多是由历史故事进行改编, 影片更需给人以历史的厚重感以及真实事件所 带来的冲击。在音效的制作上, 因为题材中有大量战争, 打斗的场景, 在音效的选择上, 则 会更突出真实以及夸张，给人带来更强的听觉冲击，让人们更能感受到历史的冲击。

画面构图作为电影艺术最为主要以及直接展现的一部分, 画面对于红色电影的作用是非 常重要的, 结合其独特的题材, 红色电影的构图多是严谨恢弘, 更直观的还原历史, 大气磅 礴的画面更直接给人带来冲击，使观众能够印象深刻。

精神内涵作为一部影片的内核, 真正能够影响到观众的内心。数量繁多的红色电影, 其 精神内涵主要涵盖了: 爱国主义、集体主义、革命精神、艰苦奋斗等传统民族精神内涵。也 正因此, 观众与红色电影的共鸣才越来越强, 红色电影的发展才会蓬勃向上。

\section{2.红色电影内在精神}

红色电影的繁荣发展对于国家与社会有着非常重要的作用。随着党和国家的伟大决策以 及持续不断深化的进行改革开放，我国的经济发展飞速向前。但与此同时，高速发展的经济 也带来了浮躁的社会氛围, 优良传统正逐渐被人们所淡忘, 我们民族的文化正慢慢蒙上灰尘。 习近平总书记所提出的文化自信是至关重要的, 红色电影的繁荣可以很大程度上的传播以及 唤醒民众内心。重新打造我们民族的文化自信。

\section{1 爱国主义}

近年来, 随着国家开放程度 的不断提高, 从国外进入中国的不仅仅只有资金与技术, 同时还有文化糟粕以及不怀好意的敌对分子。

爱国主义本就是作为一名国人所必备的信念，就如同电影《战狼》当中：境外恐怖分子 为了对中国进行恐怖袭击, 在国内运用残暴的手段采集中国人的血样, 中国军人冷锋（吴京 饰）失手打死了一名恐怖分子头目, 恐怖分子便雇佣杀手想要击杀冷锋并带走血样。在与之 战斗时, 恐怖分子侵入了中国领土, 拥有强大爱国意识的冷锋, 虽身负重伤, 但是仍寸土必 保，在他和人民军队的共同努力下赶走了侵略者，维护了国家尊严。 


\section{2 集体主义}

习近平总书记在十九大报告中指出, 要加强思想道德建设, 加强集体主义教育, 集体主 义正是在如今个人利益为上的社会中所需要的。近期大学中层出不穷的学生问题, 究其根本 主要还是个人意识太强烈, 集体意识很淡薄。在许多事情上的所作所为, 不能将个人利益与 集体利益很好的结合。

集体主义作为一项优良传统美德, 行为准则中需要的一项, 在影片《红海行动》中有着 很好的展现：该片讲述了中国海军“蛟龙突击队” 8 人小组奉命执行撤侨任务，突击队兵分两 路进行救援，在救援的过程中遇到了极其残忍的境外恐怖分子。深入敌后救援的过程中，为 了保障通讯与信号的安全, 通讯兵庄羽 (麦亨利 饰) 以一敌多, 身负重伤也绝不退缩, 最 后以自己的生命为代价, 保住了信号的安全, 为队友的凯旋归来奉献了自己。

影片中多处对于细节的描写非常震感，炸飞的手指，痛苦的表情，让人在感受到战争残 酷的同时，更对人物心生敬佩，此种集体精神正是影片所传达的。

\section{3 革命精神}

新中国是革命先辈用抛头颅洒热血的革命换来的, 革命精神也是中国特有的精神内涵之 一。大学生作为未来社会的中流砥柱, 娇生惯养的现象越来越严重, 一些基本的生活技能还 需要别人的帮助。遇到一点困难挫折寻死受活的报道越来越多。

电影《集结号》中，连长谷子地 (张涵予 饰) 带领 47 名战士，为了完成上级下达的阻 击任务，在艰苦卓绝的自然条件以及后勤保障不足的战斗条件下，拼尽最后一人也要阻挡住 敌人的脚步。

此中展现的艰苦卓绝的奋斗精神正是珍贵的革命精神, 是我们如今社会中所缺少的, 影 片中仅剩最后一人，谷子地也选择拿着炸药包与敌军同归于尽的场景非常震撼人心。正是通 过画面与声音的结合，电影将这种革命精神生动立体的展现给观众，让每一位观看过的人都 能陷入沉思。

\section{3.红色电影与当代大学生}

红色电影通过对于经典历史事件的再现与还原, 让广大大学生能够更好的了解历史事件 更好的了解那个时代。借此引发思考, 思考历史事件背后的得与失。

红色电影借由艺术本身是多种艺术相结合的特点，更直观更立体的将丰富的精神文化内 涵, 通过电影的方式传递到广大大学生的生活当中, 一改枯燥的说教, 转由通过影片引发大 学生的反思, 对大学生价值观的树立与修正具有重要意义。

\section{4.结语}

红色电影结合其自身特点, 如今活跃在国内乃至世界影坛当中。其电影本身为琳琅满目 的电影市场中再添光彩, 为电影这一艺术门类提供了更多的可能。而其对于社会的教育意义 则更为重大, 对于安抚浮躁的社会氛围有着很大的作用。为当代大学生的教育增添新的更加 有效的方式，为大学生价值观的树立与修正提供方向。为未来社会的良心发展打造良好的基 础。

\section{致谢}

本文为江西师范大学课题《红色电影对当代大学生人生观的引导作用》成果 


\section{References}

[1] Huo Tingxiao, Huang Fei. Traditional Chinese Culture and Film Art Modeling [J]. National Art Research, 2018, 31 (05): 46-53. A. Banerjee, A joint economic-lot-size model for purchaser and vendor, Decision Sciences, vol.17, pp. 292-311, 1986.

[2] Lu Yuqing, Li Xinyue, Zhao Yihan, Chen Ruoqi. Research on Cultural Communication and Contemporary Value of Red Film Based on Questionnaire and Interview of Film Consumers [J]. Reform and Opening, 2019 (06): 122-126.

[3] Liao Weihua. Research on "Red Culture" in Chinese Films [J]. Film Literature, 2018 (15): 31-33.

[4] Zhao Boyi, Li Tingting. Mekong Action: Red Film Transition and Heroic Image [J]. Film Literature, 2017 (06): 88-90.

[5] Xu Dafeng. Introduction of Martial Arts Elements in Red Movies --- Comments on Xu Ke's Edition of "Taking the Prestige of Tiger Mountain by Wisdom" [J]. Shang, 2016 (30): 216-217. 